\title{
Antidepressants in primary care: patients' experiences, perceptions, self-efficacy beliefs, and nonadherence
}

This article was published in the following Dove Press journal:

Patient Preference and Adherence

10 February 2014

Number of times this article has been viewed

\author{
Hans Wouters' \\ Marcel L Bouvy' \\ Erica CG Van Geffen' \\ Helga Gardarsdottir ${ }^{1,2}$ \\ Anne M Stiggelbout ${ }^{3}$ \\ Liset Van Dijk ${ }^{4}$ \\ 'Division of Pharmacoepidemiology \\ and Clinical Pharmacology, Faculty \\ of Science, Utrecht Institute for \\ Pharmaceutical Sciences (UIPS), \\ Utrecht University, ${ }^{2}$ Department \\ of Clinical Pharmacy, Division \\ Laboratory and Pharmacy, University \\ Medical Center Utrecht, Utrecht, \\ ${ }^{3}$ Department of Medical Decision \\ Making, Leiden University Medical \\ Center, Leiden, ${ }^{4}$ Netherlands Institute \\ for Health Services Research (NIVEL), \\ Utrecht, The Netherlands
}

Correspondence: Hans Wouters Division of Pharmacoepidemiology and Clinical Pharmacology, Faculty of Science, Utrecht Institute for Pharmaceutical Sciences (UIPS), Utrecht University, PO Box 80082, Utrecht 3508 TB,

The Netherlands

$\mathrm{Tel}+3$ I 6 I806 5473

Fax +31302539166

Email j.wouters@uu.nl
Purpose: Patient adherence to antidepressants is poor. However, this is rather unsurprising, given the equivocal efficacy, side effects, and practical problems of antidepressants. The aim of this study was to examine a wide array of patient experiences and perceptions regarding the efficacy, side effects, and practical problems of antidepressants, as well as their associations with nonadherence, and whether patients' perceived self-efficacy moderated these associations.

Patients and methods: Experiences and perceptions of 225 patients, recruited through community pharmacies, were efficiently assessed with the Tailored Medicine Inventory. Nonadherence was assessed through self-report and pharmacy refill data.

Results: Many patients were not convinced of the efficacy, thought the efficacy to be limited or did not believe antidepressants to prevent relapse, were worried about or had experienced one or more side effects, and/or had experienced one or more practical problems regarding information, intake, and packaging. Being convinced of efficacy was associated with lower intentional nonadherence (odds ratio [OR] 0.9, 95\% confidence interval [CI] 0.8-0.96). A higher number of practical problems experienced was associated with increased unintentional nonadherence (OR 1.3, 95\% CI 1.1-1.7). Higher perceived self-efficacy regarding taking antidepressants was associated with lower unintentional nonadherence (OR 0.7, 95\% CI 0.5-0.9). Perceived self-efficacy did not moderate associations of patient experiences and perceptions with nonadherence.

Conclusion: Assessing a wide array of patients' experiences and perceptions regarding the efficacy, side effects, and practical problems of antidepressants contributes to better understanding of nonadherence to antidepressants. Guiding physician-patient conversations by patients' experiences and perceptions may reduce both unintentional and intentional nonadherence. Also, it may give rise to considerations of prudent discontinuation, eg, when patients are not convinced of the efficacy.

Keywords: antidepressants, efficacy, side effects, practical problems, patients' experiences and perceptions, perceived self-efficacy, nonadherence

\section{Introduction}

There is ongoing debate about treatment with antidepressants. Two meta-analyses found antidepressants to reduce symptoms effectively ${ }^{1}$ and to prevent relapse, ${ }^{2}$ whereas another meta-analysis refuted their efficacy, except for treatment of severe depression. ${ }^{3}$ Findings from yet another study suggested that the reported successful prevention of relapse was caused by a methodological artifact. ${ }^{4}$ Furthermore, antidepressants frequently cause side effects, ${ }^{5}$ which could make the medicine worse than the ailment, especially so when the presence of side effects is paired with an absence of efficacy. Yet at the same time, many patients are treated with antidepressants. 
In the US, approximately $10 \%$ of individuals aged 12 years and older were treated with antidepressants in 2005-2008. ${ }^{6}$ In the Netherlands, which was the setting of our study, as many as 956,270 people (or $\sim 6 \%$ of the total population) were prescribed antidepressants in 2012 . $^{7}$

In view of the ambiguous findings concerning the efficacy and the reported side effects of antidepressants, the high prevalence of patients treated with antidepressants could at least in part reflect overprescribing. Indeed, an estimated $11 \%$ of patients who are treated with antidepressants in primary care do not fulfill diagnostic criteria for depressive or anxiety disorder. ${ }^{8}$ Overprescribing may also explain the substantial nonadherence rates reported in the literature. ${ }^{9,10}$ Therefore, understanding antidepressant use from the perspective of patients is of crucial importance. However, previous studies did not examine a wide array of patient experiences and perceptions with regard to antidepressant use. We therefore adopted a framework using a sensible taxonomy of experiences and perceptions regarding the efficacy and side effects of antidepressants as well as practical problems associated with their use.

We extended previous examinations ${ }^{5,9,11-13}$ in five ways. First, although previously studied patient experiences and perceptions with regard to the efficacy of antidepressants varied from perceived necessity ${ }^{11}$ and confidence of the efficacy $^{12}$ to perceived symptom relief, ${ }^{13}$ a comprehensive assessment of patient experiences and perceptions regarding the efficacy of antidepressants seems to be lacking. We therefore examined experiences and perceptions with regard to the efficacy of antidepressants in a comprehensive manner. Second, because known side effects were mostly addressed in the literature, we also addressed other side effects experienced or considered relevant by patients. Third, we examined practical problems of using antidepressants. Fourth, although many studies examined the occurrence of side effects, worries and burden caused by side effects have seldom been addressed. Fifth, in studying associations of nonadherence with patients' experiences and perceptions of antidepressants, we distinguished between intentional or conscious nonadherence versus unintentional nonadherence due to forgetting. We did so because it makes sense that unintentional and intentional nonadherence are likely to be associated with different experiences and perceptions. Such differential relationships have received little attention so far.

A concern, however, regarding extensive assessment of patients' experiences and perceptions is questionnaire burden. We therefore developed the Tailored Medicine Inventory (TMI). The TMI efficiently assesses medicine-related experiences and perceptions regarding side effects and practical problems through logical routes that allow skipping of irrelevant perceptions and experiences, thereby keeping questionnaire burden at a minimum level (see the Materials and methods section).

In addition to antidepressant-associated experiences and perceptions, we studied patients' perceived self-efficacy with regard to prolonged antidepressant use. Self-efficacy refers to patients' own perceptions of their ability to accomplish a particular behavior. ${ }^{14}$ Previously, higher perceived selfefficacy was shown to be associated with better medicine taking and less nonadherence. ${ }^{15}$

Accordingly, the objectives of this study were to assess a wide array of patients' experiences and perceptions with regard to using antidepressants, to examine which of these were associated with intentional and unintentional nonadherence, and to examine whether perceived self-efficacy moderated these associations.

\section{Materials and methods}

\section{Participants}

Patients were recruited through community pharmacies. They were invited to participate if in the previous year tricyclic antidepressants, selective serotonin reuptake inhibitors, or other antidepressants, including serotoninnorepinephrine reuptake inhibitors and tetracyclic antidepressants, had been dispensed to them. For ethical reasons, patients were not approached in cases of psychotic disorders or dementia, severe or terminal illness, or for other reasons judged to be relevant by their pharmacist, eg, psychosocial problems. Patients participated through filling out an online questionnaire. For all patients, refill data were extracted from the automated dispensing records of the pharmacy. To reduce selection bias or participation by predominantly adherent patients with access to the Internet, interviews were conducted in the pharmacy with older patients and with patients who were suspected to be nonadherent. Patients were suspected to be nonadherent if their refill histories revealed that they had missed one or more prescriptions. Clinical characteristics included status of use (being a starter or recent user versus (vs) a user or a stopper), duration and indication of treatment, having ever been admitted to a psychiatric hospital or ward, and additional treatment with psychotherapy. The medical ethical committee of the Leiden University Medical Center approved the study. All patients gave informed consent on an electronic form prior to filling out the questionnaire. 


\section{The Tailored Medicine Inventory}

As part of this study, we developed the TMI to assess patients' experiences and perceptions regarding the efficacy, side effects, and practical problems of antidepressants. These experiences and perceptions were identified through literature about nonadherence to medicines in general and to antidepressants in particular (literature references are reported in each appropriate section discussing perceptions and experiences regarding the efficacy, side effects, and practical problems). To evaluate potential paucities in the literature, we also reviewed qualitative data from face-to-face focus groups of a previous study that was conducted with primary care patients who were treated with antidepressants, reports made by patients on a website maintained by the Dutch Institute of Rational Medicine Use, ${ }^{16}$ and through information from the Summary of Product Characteristics, ${ }^{17}$ an authorization document for medicines of the European Medicines Agency. Four pharmacists and a psychiatrist reviewed the content of the items. The items were written at a difficulty level requiring 8-9 years of formal education using the Flesch-Kincaid formula. ${ }^{18}$ Experiences and perceptions with regard to side effects and practical problems were efficiently assessed by means of logical routes (Figure 1). These routes enabled us to assess experiences and perceptions in a manner that was comprehensive but also efficient. To avoid order effects, items and item categories were presented in random order wherever appropriate. A pilot study was conducted among nine volunteers and eleven patients to assess item content, upon which we concluded that only minor rewording of items was necessary.

\section{TMI: experiences and perceptions with regard to the efficacy of antidepressants}

Experiences and perceptions with regard to the efficacy of antidepressants were assessed with regard to relapse prevention, being convinced of the efficacy and perceived necessity, education about efficacy, as well as symptomatic efficacy $^{11,12,16,19-22}$ (see Table S1).

Responses to each statement were scored on 5-point scales ( 0 , fully disagree; 4 , fully agree). Consistent with the categories of experiences and perceptions, factor analysis (varimax rotation) revealed four dimensions: being convinced of the efficacy (five items), education about efficacy (three items), relapse prevention (four items), and symptomatic efficacy (four items). As the internal consistencies were insufficient for the dimensions of education about efficacy $(\alpha=0.69)$ and relapse prevention $(\alpha=0.62)$, these dimensions were not further studied. The dimension of being convinced of the efficacy had high internal consistency after removal of one item $(\alpha=0.84$, scoring range $0-16)$ and the symptomatic efficacy dimension had sufficient internal consistency also after removal of one item $(\alpha=0.78$, scoring 0-12) (Table S1).
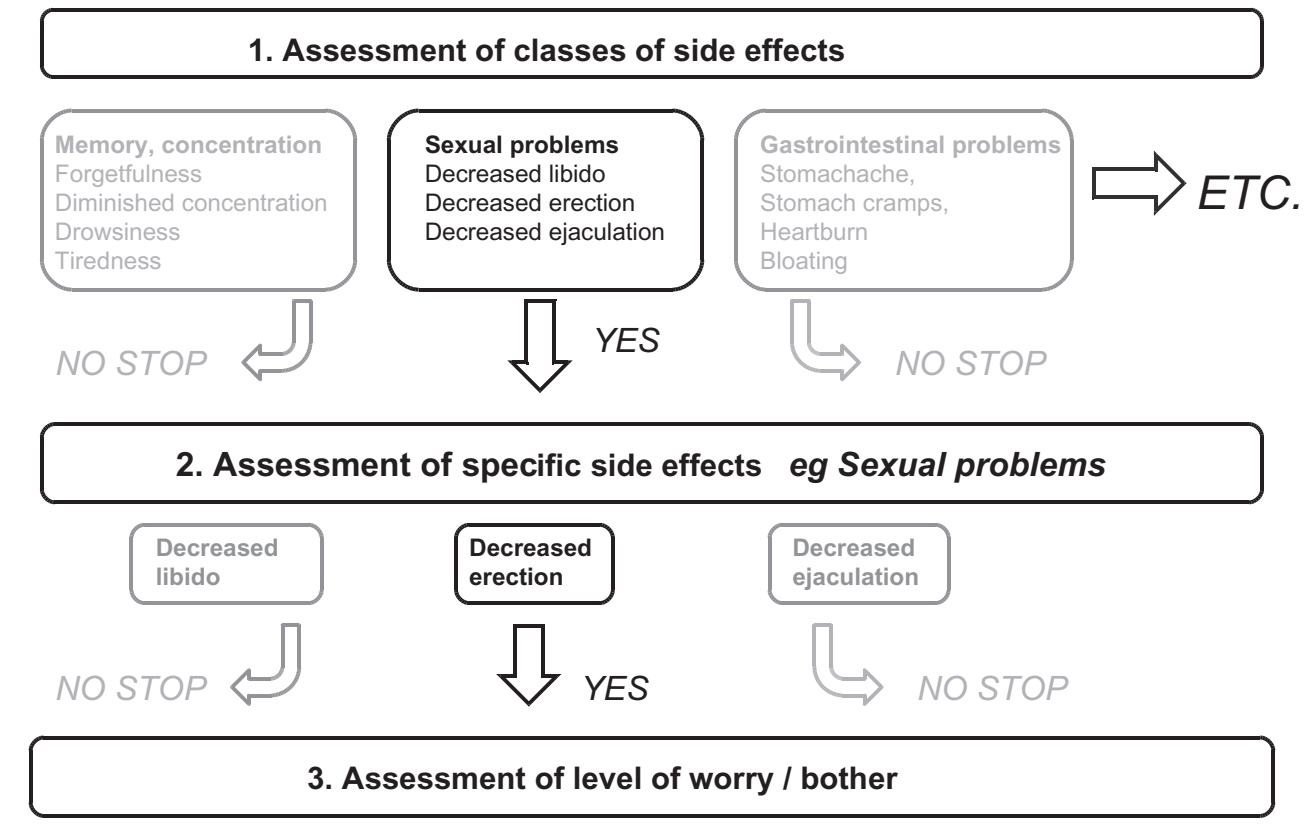

Figure I Illustration of three-step method to assess efficiently a comprehensive list of side effects. 


\section{TMI: worries about and experiences with side effects of antidepressants}

Worries about side effects were assessed for known side effects of antidepressants that included dizziness, gastrointestinal complaints, dry mouth, sweating, emotional flatness, insomnia, drowsiness, tiredness, decreased libido, and for male patients also problems with erection and ejaculation. ${ }^{5,13,17}$ Experiences with these known side effects and less well-known side effects of antidepressants were assessed with a comprehensive checklist consisting of side effects with regard to memory and concentration, gynecologic complaints (in women), restlessness, skin and hair problems, heart or bladder problems, gastrointestinal problems, and muscle and joint complaints..$^{5,13,17,23,24}$ To avoid test burden, experiences with regard to side effects were efficiently assessed in a three-step manner enabled by logical routes (see Figure 1 for an illustration). First, we presented the classes of side effects. Patients had to indicate which class or classes of side effects they had experienced. To avoid reporting bias, the specific side effects belonging to a class were displayed in parentheses behind that class. Subsequently, for each endorsed class of side effects, patients had to indicate which specific side effect or side effects they had experienced. Finally, for the side effect or side effects that a patient had experienced, he or she had to indicate the level of bother. Worries about side effects were also efficiently assessed but in a two-step manner adopting only steps 2 and 3 of the approach shown in Figure 1. Levels of bother and worry were assessed on a 5-point scale (1, not bothersome/worrying at all; 5, very bothersome/worrying).

\section{TMI: experiences with regard to practical aspects of antidepressant use}

Practical problems of antidepressant use were also assessed in a tailored manner analogous to the assessment of experience of side effects. The comprehensive checklist of practical problems consisted of specific problems with regard to written information, ${ }^{15,25}$ logistical problems such as availability and getting refills, ${ }^{24}$ dosage and intake, ${ }^{24-26}$ packaging, ${ }^{25}$ and other problems. ${ }^{27}$ Here too, level of bother was assessed on a 5-point scale (1, not bothersome at all; 5, very bothersome).

\section{Perceived self-efficacy}

Perceived self-efficacy with regard to medicine taking and learning about medication was assessed with the eight-item Medication Understanding and Use Self-Efficacy Scale
(MUSE) scale. ${ }^{15}$ Internal consistencies $(\alpha)$ were 0.84 for perceived self-efficacy with regard to taking medication (four items, scoring range $0-12$ ), and 0.83 with regard to learning about medication (four items, scoring range $0-12$ ).

\section{Therapy nonadherence}

Self-reported nonadherence to antidepressants was assessed with items from the Medication Adherence Rating Scale (MARS-5).$^{28}$ Because the MARS-5 seemed to measure predominantly intentional nonadherence and unintentional nonadherence seemed to be underrepresented, assessment of nonadherence was complemented with the new Morisky Medication Adherence Scale (MMAS-8), ${ }^{29}$ and additional questions about forgetting to take antidepressants and persistence. As we were interested in unintentional and intentional nonadherence as underlying dimensions, we did not calculate total scores on the instruments. Rather, we pooled both instruments and the additional questions, and subjected the data to factor analysis. Factor analysis (varimax rotation) and internal consistency measures indeed confirmed that the items measured unintentional nonadherence due to forgetfulness and intentional or deliberate nonadherence as underlying dimensions. Accordingly, for every patient, an unintentional nonadherence total score was calculated by summing the items measuring unintentional nonadherence and an intentional nonadherence total score by summing the items measuring intentional nonadherence (Table S2). In addition, overall nonadherence was inferred from the pharmacy refill data. To that end, a Medication Possession Ratio (MPR) was calculated using information on antidepressant dispensing data prior to the date on which patients were recruited for the study. We followed the methodology previously described and tested by Gardarsdottir et al. ${ }^{30}$ So-called treatment episodes were calculated by allowing 90-day gaps or the duration of a standard prescription in the Netherlands between the theoretical end date of an antidepressant prescription and a successive antidepressant prescription. Where the dispensing date of the successive antidepressant prescription preceded the theoretical end date of the prior prescription, this overlap was accounted for. The MPR was calculated for the last treatment episode of each patient prior to recruitment.

\section{Statistical analysis}

Because the total scores of unintentional and intentional nonadherence were skewed, these were dichotomized at $<80 \%$ vs $\geq 80 \%$ of the score distribution (unintentional nonadherence, score of $\leq 2$ vs $\geq 3$; intentional nonadherence, score of $\leq 3$ vs $\geq 4$ ). Associations between intentional 
and unintentional nonadherence and the following variables were first examined in a series of univariate logistic regression analyses: demographic and clinical characteristics, the extent to which patients were convinced of the efficacy and perceived symptomatic efficacy, the number of side effects patients were worried about and that they had experienced, the number of experienced practical problems, and perceived self-efficacy. Variables that had a univariate association with nonadherence $(P<0.10)$ were subsequently entered into multivariate regression models as independent variables. For each significant independent variable, we subsequently included an interaction term between that variable and perceived self-efficacy with regard to taking and/or learning about antidepressants. Subsequently, these analyses were repeated with the MPR calculated from the pharmacy refill data (MPR) as the dependent variable (adherent $\geq 80 \%$ vs nonadherent $<80 \%$ ). All analyses were done with SPSS software (IBM Corporation, Armonk, NY, USA).

\section{Results}

Table 1 presents the demographic and clinical characteristics of the 225 men and women who participated.

Table I Demographic and clinical characteristics of the participants $(n=225)$

\begin{tabular}{|c|c|}
\hline Variables & Statistic \\
\hline \multicolumn{2}{|l|}{ Demographic characteristics } \\
\hline Women, n (\%) & $149(66)$ \\
\hline Mean age, years (SD) & $51.1(13.5)$ \\
\hline Married or living together, n (\%) & $176(78)$ \\
\hline Higher educated (vs low to medium), n (\%) & $57(25)$ \\
\hline \multicolumn{2}{|l|}{ Clinical characteristics } \\
\hline \multicolumn{2}{|l|}{ Status of use, $n(\%)$} \\
\hline Starters and recent users $<3$ months & $18(8)$ \\
\hline Users $>3$ months & $183(8 \mid)$ \\
\hline Stoppers & $24(I I)$ \\
\hline \multicolumn{2}{|l|}{ Duration of use (only users $>3$ months), $n(\%)$} \\
\hline $0-1$ years & $26(14)$ \\
\hline $1-4$ years & $37(20)$ \\
\hline 4 years or longer & $120(66)$ \\
\hline \multicolumn{2}{|l|}{ Type of antidepressant, n (\%) } \\
\hline TCA & $38(17)$ \\
\hline SSRI & $137(6 \mid)$ \\
\hline Other $^{\mathrm{a}}$ & $50(22)$ \\
\hline \multicolumn{2}{|l|}{ Indication for use, n (\%) } \\
\hline Depression & $134(60)$ \\
\hline Anxiety or panic & $103(46)$ \\
\hline Otherwise & $82(36)$ \\
\hline Ever been admitted to psychiatric hospital/ward, n (\%) & $14(6)$ \\
\hline Additional treatment with psychotherapy, n (\%) & $84(37)$ \\
\hline
\end{tabular}

Ample variation was observed for most demographic and clinical characteristics. About two-thirds of the patients were treated with antidepressants for $\geq 4$ years, over half were treated with a selective serotonin reuptake inhibitor, and over a third were treated with additional psychotherapy.

\section{Experiences and perceptions with regard to the efficacy of antidepressants}

Negative or neutral experiences and perceptions (disagree and neutral vs agree) with regard to the efficacy of antidepressants were reported by many patients (see Table 2). Over $10 \%$ of patients doubted the efficacy, a third were not convinced of the efficacy, did not believe the use of antidepressants to be necessary, or thought the efficacy to be limited, four of ten

Table 2 Experiences and perceptions with regard to the efficacy of antidepressants

\begin{tabular}{|c|c|c|c|c|}
\hline & \multicolumn{2}{|c|}{$\begin{array}{l}\text { Disagree } \\
\text { and neutral }\end{array}$} & \multicolumn{2}{|c|}{ Agree } \\
\hline & $\mathbf{n}$ & $\%$ & $\mathbf{n}$ & $\%$ \\
\hline $\begin{array}{l}\text { I. The use of antidepressants } \\
\text { is necessary for me }\end{array}$ & 64 & 28 & 161 & 72 \\
\hline $\begin{array}{l}\text { 2. I am convinced of the efficacy } \\
\text { of antidepressants }\end{array}$ & 73 & 32 & 152 & 68 \\
\hline $\begin{array}{l}\text { 3. I have doubts about the efficacy } \\
\text { of antidepressants }\end{array}$ & 193 & 86 & 32 & 14 \\
\hline $\begin{array}{l}\text { 4. Antidepressants have a limited } \\
\text { efficacy }\end{array}$ & 152 & 68 & 73 & 32 \\
\hline 5. I expect antidepressants to help & 68 & 30 & 157 & 70 \\
\hline 6. I know how antidepressants work & 80 & 36 & 145 & 64 \\
\hline $\begin{array}{l}\text { 7. I received information about } \\
\text { how antidepressants work }\end{array}$ & 65 & 29 & 160 & 71 \\
\hline $\begin{array}{l}\text { 8. I know why I have to use } \\
\text { antidepressants }\end{array}$ & 25 & 11 & 200 & 89 \\
\hline $\begin{array}{l}\text { 9. I am using antidepressants, } \\
\text { because I was afraid my } \\
\text { complaints would come back }\end{array}$ & 102 & 45 & 122 & 55 \\
\hline $\begin{array}{l}\text { 10. Antidepressants prevent my } \\
\text { complaints from coming back }\end{array}$ & 92 & 41 & 133 & 59 \\
\hline $\begin{array}{l}\text { II. Using antidepressants resolves } \\
\text { your problems }\end{array}$ & $|5|$ & 67 & 74 & 33 \\
\hline $\begin{array}{l}\text { 12. The longer you use antidepressants, } \\
\text { the better they work }\end{array}$ & 164 & 73 & 61 & 27 \\
\hline $\begin{array}{l}\text { 13. It took a long time, before my } \\
\text { antidepressants worked }\end{array}$ & 154 & 69 & 70 & 31 \\
\hline $\begin{array}{l}\text { 14. Owing to antidepressants, } \\
\text { I have more energy }\end{array}$ & 140 & 62 & 84 & 37 \\
\hline $\begin{array}{l}\text { 15. Owing to antidepressants, } \\
\text { I sleep better }\end{array}$ & 128 & 57 & 96 & 43 \\
\hline $\begin{array}{l}\text { 16. Because of my antidepressants, } \\
\text { I feel physically better }\end{array}$ & 109 & 48 & 115 & 51 \\
\hline $\begin{array}{l}\text { 17. Because of my antidepressants, } \\
\text { I feel mentally better }\end{array}$ & 60 & 27 & 164 & 73 \\
\hline
\end{tabular}


patients did not believe antidepressants to prevent relapse, and a third did not expect antidepressants to help. One in ten patients did not know why they had to use antidepressants, a third had not received information about the efficacy and/ or did not know how antidepressants worked. A quarter of the patients did not feel mentally better, half did not feel physically better, nearly two-thirds did not get more energy, and more than half did not sleep better, whereas two-thirds did not believe antidepressants to resolve their problems and a third thought it took a long time before antidepressants worked. The mean total scores on the dimensions of being convinced of efficacy and symptomatic efficacy were 11.7 (standard deviation [SD] 3.7, observed range 0-16) and 7.3 (SD 3.1, observed range 0-12) respectively.

\section{Worries about and experiences with side effects of antidepressants}

Patients were worried on average about three side effects (SD 2) and had experienced on average four side effects (SD 4). Table 3 presents the known side effects of antidepressants (both worry and experience assessed) and less-known and other side effects (only experience assessed).

Table 3 Worries about and experiences of side effects of antidepressants

\begin{tabular}{|c|c|c|c|c|}
\hline \multirow[t]{2}{*}{ Side effects } & \multicolumn{2}{|c|}{ Worry about side effects } & \multicolumn{2}{|c|}{ Experiences of side effects } \\
\hline & $\begin{array}{l}\text { Yes, } \\
\text { n (\%) }\end{array}$ & $\begin{array}{l}\text { M level of } \\
\text { worry (SD) }\end{array}$ & $\begin{array}{l}\text { Yes, } \\
\text { n (\%) }\end{array}$ & $\begin{array}{l}\text { M level of } \\
\text { bother (SD) }\end{array}$ \\
\hline \multicolumn{5}{|l|}{ Side effects associated with antidepressants } \\
\hline Dizziness & $40(18)$ & $2.8(1.2)$ & $16(7)$ & $4.1(1.1)$ \\
\hline Vomiting/feeling nauseous & $9(4)$ & $2.6(1.3)$ & $6(3)$ & $4.2(1.0)$ \\
\hline Gastrointestinal complaints & $37(16)$ & $2.6(1.4)$ & $23(10)$ & $4.6(0.8)$ \\
\hline Dry mouth & $53(24)$ & $2.3(1.3)$ & $50(22)$ & $3.7(1.2)$ \\
\hline Sweating & $55(24)$ & $2.7(1.2)$ & $42(19)$ & $4.4(0.7)$ \\
\hline Emotional flatness & $54(24)$ & $3.1(1.2)$ & $42(19)$ & $4.1(1.1)$ \\
\hline Insomnia & $23(10)$ & $3.3(1.2)$ & $29(13)$ & $4.5(0.8)$ \\
\hline Drowsiness & $50(22)$ & $3.5(1.2)$ & $36(16)$ & $4.1(1.0)$ \\
\hline Tiredness & $68(30)$ & $3.3(1.3)$ & $52(23)$ & $4.3(0.9)$ \\
\hline Libido decrease & $95(42)$ & $3.4(1.3)$ & $84(37)$ & $4.2(1.1)$ \\
\hline Decreased erection or ejaculation & $33(15)$ & $3.5(1.1)$ & $28(12)$ & $3.3(1.1)$ \\
\hline \multicolumn{5}{|l|}{ Other side effects } \\
\hline \multicolumn{5}{|l|}{ Memory, concentration or tiredness } \\
\hline Forgetfulness & & & $42(19)$ & $4.4(0.8)$ \\
\hline Diminished concentration & & & $37(16)$ & $4.4(0.6)$ \\
\hline \multicolumn{5}{|l|}{ Gynecological complaints } \\
\hline Painful or sensitive breasts & & & $8(4)$ & $3.8(1.0)$ \\
\hline Vaginal discharge, vaginal dryness, or vaginal itch & & & II (5) & $3.9(1.0)$ \\
\hline Hot flushes & & & $18(8)$ & $4.1(0.9)$ \\
\hline Vaginal blood loss & & & I $(0.4)$ & 5 (NA) \\
\hline \multicolumn{5}{|l|}{ Emotional } \\
\hline Feeling restless & & & $33(15)$ & $4.6(0.6)$ \\
\hline \multicolumn{5}{|l|}{ Skin or hair } \\
\hline Hair loss & & & $15(7)$ & $4.0(0.9)$ \\
\hline Rash & & & $12(5)$ & $4.5(0.5)$ \\
\hline \multicolumn{5}{|l|}{ Heart, vessels, or bladder } \\
\hline Heart palpitations & & & $16(7)$ & $4.3(0.9)$ \\
\hline Edema & & & $16(7)$ & $4.4(0.8)$ \\
\hline Urinary retention & & & $8(4)$ & $3.8(1.6)$ \\
\hline Incontinence & & & $14(6)$ & $4.5(0.9)$ \\
\hline \multicolumn{5}{|l|}{ Gastrointestinal problems } \\
\hline Stomach ache, stomach cramps, heartburn, or bloating & & & $28(12)$ & $4.4(0.6)$ \\
\hline \multicolumn{5}{|l|}{ Muscles, bones, or joints } \\
\hline Ache, stiffness, swelling, or inflammation of joints & & & $34(15)$ & $4.4(0.7)$ \\
\hline Trembling & & & $17(8)$ & $4.2(0.9)$ \\
\hline Backache & & & $23(10)$ & $4.5(0.7)$ \\
\hline Muscular pain or muscle cramps & & & $33(15)$ & $4.4(0.8)$ \\
\hline
\end{tabular}

Note: assessed on a scale ranging from I to 5 .

Abbreviations: SD, standard deviation; NA, not available; M, mean. 


\section{Worry about side effects}

Many patients expressed worry about libido decrease, tiredness, emotional flatness, sweating, and a dry mouth (see Table 3). Mean levels of worry were on average moderate to high, varying between patients but equal for most side effects.

\section{Experience of side effects}

Most frequently experienced known side effects of antidepressants were libido decrease, tiredness, feeling drowsy, insomnia, emotional flatness, sweating, a dry mouth, gastrointestinal complaints, and decreased erection or ejaculation (see Table 3). Other side effects that were also often experienced were forgetfulness, diminished concentration, feeling restless, and musculoskeletal complaints. Fewer patients experienced side effects, such as incontinence, urinary retention, edema, rash, hair loss, vaginal discharge, dryness, or itch, and painful breasts. Most side effects posed substantial bother to the patients, but there was also individual variation in the level of bother.

\section{Experience of practical problems of antidepressant use}

A total of 115 patients (52\%) had experienced one or more practical problems. The most frequently experienced practical problems concerned information of leaflets, intake of tablets, and packaging. Together with logistical problems (eg, refill problems), these posed the greatest levels of bother (see Table 4).

\section{Therapy nonadherence}

Increasing age was associated with a lower likelihood of unintentional nonadherence. A higher number of practical problems experienced was associated with an increased likelihood of

Table 4 Experiences of practical problems of antidepressant use

\begin{tabular}{lll}
\hline Practical problems & $\begin{array}{l}\text { Yes, } \\
\mathbf{n}(\%)\end{array}$ & $\begin{array}{l}\text { M level of } \\
\text { bother (SD) }\end{array}$ \\
\hline $\begin{array}{lll}\text { Information, }{ }^{\mathrm{a}} \text { intake of tablets, } \\
\text { and packaging and blister }\end{array}$ & $62(28)$ & $3.5(0.9)$ \\
Logistical problems $^{\mathrm{b}}$ & & \\
Limitations in daily life $^{\mathrm{e}}$ & $47(2 \mathrm{I})$ & $3.6(\mathrm{I} .0)$ \\
Medication interaction $^{\mathrm{f}}$ & $46(20)$ & $2.9(0.9)$ \\
\hline
\end{tabular}

Notes: ${ }^{a}$ Contradictory, redundant, small font size, text comprehension; btablets how to take, number of tablets in blister impractical, needed to be broken for correct dose, were difficult to break or to swallow, taste, took a long time to get correct dose, use difficult to fit into daily routine, dose skipping; 'unclear label, difficulties regarding opening package, pressing tablets out of blister or cutting part of blister, changes of package, medicine name change, tablet color/form; dantidepressants unavailable or unclear how to get refills, getting insufficient antidepressant tablets, having to go too often to pharmacist or physician; ${ }^{e}$ whether antidepressant use permitted alcohol consumption and affected driving ability negatively; 'medicine interactions; assessed on a scale ranging from I to 5 .

Abbreviation: SD, standard deviation; M, mean. unintentional nonadherence. Being convinced of the efficacy was associated with lower intentional nonadherence. Increased perceived self-efficacy with regard to taking antidepressants was associated with lower unintentional nonadherence. Because perceived self-efficacy was not associated with intentional nonadherence, analysis of moderating influence of perceived self-efficacy was restricted to unintentional nonadherence. No moderating effects of perceived self-efficacy on associations between experiences and perceptions with regard to antidepressants and unintentional nonadherence were found (data not shown). Turning to nonadherence as assessed with the MPR calculated from the refill data, it was shown that only longer duration of treatment with antidepressants was associated with increased nonadherence (see Table 5).

\section{Discussion}

Our findings demonstrate that a substantial number of patients expressed doubts about efficacy and were worried

Table 5 Multivariate logistic regression results: associations of unintentional and intentional nonadherence with patients' experiences and perceptions with regard to antidepressant use

\begin{tabular}{|c|c|c|c|}
\hline \multirow[t]{3}{*}{ Predictors } & \multicolumn{3}{|l|}{ Nonadherence } \\
\hline & Unintentional & Intentional & MPR \\
\hline & $\begin{array}{l}\text { Odds ratio } \\
(95 \% \mathrm{CI})\end{array}$ & $\begin{array}{l}\text { Odds ratio } \\
(95 \% \mathrm{Cl})\end{array}$ & $\begin{array}{l}\text { Odds ratio } \\
(95 \% \mathrm{Cl})\end{array}$ \\
\hline Age & $0.95(0.91-0.99)^{\dagger}$ & & \\
\hline \multicolumn{4}{|l|}{ Marital status } \\
\hline $\begin{array}{l}\text { Not married/ } \\
\text { divorced/ } \\
\text { widow(er) }\end{array}$ & Reference & & \\
\hline $\begin{array}{l}\text { Married/living } \\
\text { together }\end{array}$ & $1.2(0.4-4.2)$ & & \\
\hline Duration of use & & & $1.9(1.04-3.5)^{*}$ \\
\hline $\begin{array}{l}\text { Overall } \\
\text { efficacy score }\end{array}$ & $0.99(0.92-1.06)$ & & \\
\hline $\begin{array}{l}\text { Convinced of } \\
\text { efficacy score }\end{array}$ & & $0.9(0.8-0.96)^{\dagger}$ & \\
\hline $\begin{array}{l}\text { Number of } \\
\text { side effects } \\
\text { experienced }\end{array}$ & & & $0.9(0.7-1.0)$ \\
\hline \multicolumn{4}{|c|}{ Emotional side effects } \\
\hline No & Reference & Reference & \\
\hline Yes & $1.4(0.5-4.2)$ & I.8 (0.9-4.0) & \\
\hline $\begin{array}{l}\text { Number of } \\
\text { practical } \\
\text { problems } \\
\text { experienced }\end{array}$ & $1.3(1.1-1.7)^{*}$ & I.I $(0.9-1.3)$ & \\
\hline $\begin{array}{l}\text { Taking self- } \\
\text { efficacy (MUSE) }\end{array}$ & $0.7(0.5-0.9)^{\dagger}$ & & \\
\hline $\begin{array}{l}\text { Learning self- } \\
\text { efficacy (MUSE) }\end{array}$ & $1.2(0.8-1.7)$ & & \\
\hline
\end{tabular}

Notes: $* P<0.05 ;{ }^{\dagger} p<0.01$.

Abbreviations: MPR, medication possession ratio; $\mathrm{Cl}$, confidence interval; MUSE, Medication Understanding and Use Self-Efficacy Scale. 
about or had experienced side effects, particularly decreased libido, tiredness, feeling drowsy, insomnia, emotional flatness, sweating, a dry mouth, and intestinal complaints. These side effects were consistent with those reported in the literature. ${ }^{13,16}$ Furthermore, the high levels of evoked worry and bother suggest that most side effects imposed a nonnegligible burden. At the same time, there was considerable individual variation in these levels of evoked worry and bother. In addition, roughly half the patients had experienced one or more problems of a practical nature.

That being convinced of the efficacy was associated with lower intentional nonadherence seems obvious. However, a less obvious result was that worry about or experience of side effects was not associated with nonadherence. Previous findings regarding prediction of nonadherence by experience of side effects were contradictory. ${ }^{5,12}$ Perhaps only side effects that are substantially bothering are predictive of nonadherence. Furthermore, practical problems were found to increase the likelihood of unintentional nonadherence. Consistent with findings by Cameron et al, ${ }^{15}$ perceived self-efficacy was predictive of nonadherence; in our case, unintentional nonadherence. However, perceived selfefficacy did not moderate associations of nonadherence with experiences and perceptions. Therefore, higher perceived self-efficacy seems to promote adherence regardless of whether antidepressant-related experiences and perceptions were favorable or unfavorable. The finding that a decrease of unintentional nonadherence was associated with increasing age was consistent with a previous finding. ${ }^{22}$ That experiences and perceptions were not predictive of nonadherence as assessed with the MPR calculated from the pharmacy refill data was an unexpected finding at first sight. Yet on closer inspection, a plausible explanation for this finding could be that the MPR reflects both unintentional and intentional nonadherence, whereas different experiences and perceptions were shown to be differentially related to unintentional and intentional nonadherence.

Understanding patients' experiences and perceptions with regard to antidepressant use is important, as it could serve a dual purpose. First, it is likely to decrease patients' failure to adhere to treatment with antidepressants. For patients who wish to continue treatment, better coping with resolving practical barriers and boosting perceived self-efficacy are likely to decrease nonadherence. Second, it might actually prevent overprescribing of antidepressants. Overprescribing of antidepressants is plausible. Meta-analytic findings regarding the efficacy of antidepressants were equivocal, ${ }^{1-3}$ antidepressants are known to cause multiple side effects, ${ }^{5}$ the rates of nonadherence reported in the literature are high,, 10 and a recent study found that as many as $11 \%$ of primary care patients who are treated with antidepressants do not fulfill criteria for depressive or anxiety disorder. ${ }^{8}$ Knowing patients' perceptions and experiences with regard to antidepressants could therefore offer possible explanations for patients' refusal of an overprescribed medicine, although it should be noted that we did not find experience of side effects to be associated with nonadherence. Therefore, for patients with mild depression who are not convinced of the efficacy of antidepressants, prudent discontinuation should be contemplated too. Such a patient-centered approach would be an interesting future avenue for clinical practice and research.

Our findings have other implications for clinicians too. First, our findings revealed that most side effects impose a moderate-to-high burden and that less well-known side effects of antidepressants were experienced too. This indicates the need to look broadly at a wide array of side effects. Second, the finding that the levels of evoked worry and bother varied substantially among individual patients indicates the need to complement assessments of mere occurrence of side effects with the level of worry and bother evoked by these side effects, both in study settings and in clinical practice. Third, although practical problems have received less attention in the literature, the fact that experiencing practical problems was associated with an increased likelihood of unintentional nonadherence underlines the need for physicians and pharmacists to closely monitor these in addition to side effects.

There were various strengths to assessing experiences and perceptions using the TMI. First, development of the TMI was based on thorough review of the literature and findings from focus groups. Second, with regard to side effects, we not only addressed experiences but also worry about side effects. Third, our efficient administration of the questionnaire, ie, skipping irrelevant items, is new in this field. For clinicians and researchers, the obvious advantage is that our instrument enables assessment of a wide array of experiences and perceptions simultaneously. This reduces the chance of overlooking crucial ones and diminishes confounding in the analysis. At the same time, questionnaire burden is probably prevented. Because there seems not to be a single cause of nonadherence, ${ }^{31}$ and different perceptions or negative experiences may explain nonadherence for different patients, assessing a wide array of experiences and perceptions is likely to be unavoidable. The TMI or similar methodologies therefore deserve adoption in future research. Consistent with the notion that different perceptions or negative experiences 
may explain nonadherence for different patients is the finding from a systematic review showing no consistent indications for which interventions may be effective. ${ }^{9}$ It is therefore more likely that individually tailored interventions targeting the specific problems of a patient are more efficacious. In this regard, we would recommend employment of the TMI as a boon to get insight into patients' misperceptions and specific problems as an impetus for such individually tailored adherence-improving interventions. Besides nonadherence, another instance where input from the TMI could be valuable are decisions to switch to another antidepressant. Other strengths of the study were that there was ample variation in patients' demographic and clinical characteristics, and that the major types of antidepressants were studied.

There were also limitations. Clinical characteristics were assessed by self-report and such characteristics as comorbid medical conditions, personality disorders, and other Axis II disorders and substance abuse could not be assessed. Furthermore, we did not study interpersonal factors, such as the patient-physician relationship, degree of involvement in treatment decisions, physician attitudes toward antidepressants, and such disease factors as severity of the disease, social stigma, and patient's beliefs about the disease. However, this was done to focus our study on experiences and perceptions directly related to medicine use. Moreover, studying both medicine-related perceptions and interpersonal factors in one questionnaire was likely to confound interpersonal and disease factors with medicine-specific perceptions and experiences.

Assessment of nonadherence has potential shortcomings. Self-reported intentional nonadherence is liable to social desirability bias and perhaps self-serving bias too. Selfreported unintentional nonadherence is necessarily limited to the instances of forgetting that were afterwards remembered by participants. On the other hand, limitations of inferring nonadherence from pharmacy refill data are that this does not permit distinction between unintentional and intentional nonadherence and that it does not guarantee that patients actually take their antidepressants. This is why we inferred nonadherence from both self-report and refill data. Furthermore, selection bias may have occurred. In this regard though, the ample variance in relevant demographic and clinical background variables of our sample was reassuring. Finally, a limitation with respect to study design was that the study was cross-sectional rather than longitudinal. As a result, we could not study changes in experiences and perceptions as well as incident nonadherence and discontinuation.

\section{Conclusion}

Taken together, insight into a wide array of patients' experiences and perceptions with regard to antidepressants is likely to contribute to better understanding of antidepressants from the perspective of patients. This is likely to improve nonadherence. At the same time, discontinuation of antidepressants should be contemplated for patients with mild complaints who are not convinced of their efficacy.

\section{Author contributions}

All authors jointly developed the manuscript content and were involved in at least one of the following: conception, design, data acquisition, analysis, statistical analysis, interpretation of data, drafting the manuscript and/or revising the manuscript for important intellectual content. All authors provided final approval of the version to be published.

\section{Acknowledgments}

We kindly thank all study participants for their participation. We kindly thank Ms Gemma Maatman, Ms Nina Winter, the community pharmacists, and the pharmacy interns for their assistance with regard to collecting the data. We kindly thank the volunteers for filling out the questionnaire. The work presented in this paper was financially supported by a grant from The Netherlands Organization for Health Research and Development (ZonMw) (grant 152002028).

\section{Disclosure}

Dr Liset van Dijk has received two unrestricted grants from AstraZeneca and BMS. Dr Erica CG van Geffen is now employed at the Dutch Kidney Foundation (Nierstichting). The other authors report no conflicts of interest in this work.

\section{References}

1. Gibbons RD, Hur K, Brown CH, Davis JM, Mann JJ. Benefits from antidepressants: synthesis of 6-week patient-level outcomes from doubleblind placebo-controlled randomized trials of fluoxetine and venlafaxine. Arch Gen Psychiatry. 2012;69:572-579.

2. Geddes JR, Carney SM, Davies C, et al. Relapse prevention with antidepressant drug treatment in depressive disorders: a systematic review. Lancet. 2003;361:653-661.

3. Kirsch I, Deacon BJ, Huedo-Medina TB, Scoboria A, Moore TJ, Johnson BT. Initial severity and antidepressant benefits: a meta-analysis of data submitted to the Food and Drug Administration. PLoS Med. 2008;5:e45.

4. Gardarsdottir H, Egberts TC, Stolker JJ, Heerdink ER. Duration of antidepressant drug treatment and its influence on risk of relapse/ recurrence: immortal and neglected time bias. Am J Epidemiol. 2009;170: 280-285.

5. Uher R, Farmer A, Henigsberg N, et al. Adverse reactions to antidepressants. Br J Psychiatry. 2009;195:202-210. 
6. Pratt LA, Brody DJ, Gu Q. NCHS data brief: antidepressant use in persons aged 12 and over: United States, 2005-2008. NCHS Data Brief. 2011:1-8.

7. GIP Databank [website on the Internet]. Available from: http://www. gipdatabank.nl. Accessed December 6, 2013.

8. Rubio-Valera M, Fernández A, Luciano JV, et al. Psychotropic prescribing in Catalonia: results from an epidemiological study. Fam Pract. 2012;29:154-162.

9. Pampallona S, Bollini P, Tibaldi G, Kupelnick B, Munizza C. Patient adherence in the treatment of depression. Br J Psychiatry. 2002;180: 104-109.

10. Ten Doesschate MC, Bockting CL, Schene AH. Adherence to continuation and maintenance antidepressant use in recurrent depression. $J$ Affect Disord. 2009;115:167-170.

11. Aikens JE, Nease DE, Nau DP, Klinkman MS, Schwenk TL. Adherence to maintenance-phase antidepressant medication as a function of patient beliefs about medication. Ann Fam Med. 2005;3:23-30.

12. Brook OH, van Hout HP, Stalman WA, de Haan M. Nontricyclic antidepressants: predictors of nonadherence. J Clin Psychopharmacol. 2006;26:643-647.

13. Masand PS. Tolerability and adherence issues in antidepressant therapy. Clin Ther. 2003;25:2289-2304.

14. Bandura A, Locke EA. Negative self-efficacy and goal effects revisited. J Appl Psychol. 2003;88:87-99.

15. Cameron KA, Ross EL, Clayman ML, et al. Measuring patients' selfefficacy in understanding and using prescription medication. Patient Educ Couns. 2010;80:372-376.

16. Van Geffen EC, van der Wal SW, van Hulten R, de Groot MC, Egberts AC, Heerdink ER. Evaluation of patients' experiences with antidepressants reported by means of a medicine reporting system. Eur J Clin Pharmacol. 2007;63:1193-1199.

17. European Medicines Agency. Summary of product characteristics. 2012. Available from: http://www.ema.europa.eu. Accessed.

18. Flesh R. A new readability yardstick. J Appl Psychol. 1948;32: 221-233.

19. Wolf MS, Davis TC, Osborn CY, Skripkauskas S, Bennett CL, Makoul G. Literacy, self-efficacy, and HIV medication adherence. Patient Educ Couns. 2007;65:253-260.
20. Silliman RA, Guadagnoli E, Rakowski W, et al. Adjuvant tamoxifen prescription in women 65 years and older with primary breast cancer. J Clin Oncol. 2002;20:2680-2688.

21. Jonsdottir H, Friis S, Horne R, Pettersen KI, Reikvam A, Andreassen OA. Beliefs about medications: measurement and relationship to adherence in patients with severe mental disorders. Acta Psychiatr Scand. 2009;119:78-84.

22. Sirey JA, Bruce ML, Alexopoulos GS, Perlick DA, Friedman SJ, Meyers BS. Stigma as a barrier to recovery: perceived stigma and patient-rated severity of illness as predictors of antidepressant drug adherence. Psychiatr Serv. 2001;52:1615-1620.

23. Fink AK, Gurwitz J, Rakowski W, Guadagnoli E, Silliman RA. Patient beliefs and tamoxifen discontinuance in older women with estrogen receptor-positive breast cancer. J Clin Oncol. 2004;22:3309-3315.

24. Mann DM, Allegrante JP, Natarajan S, Halm EA, Charlson M. Predictors of adherence to statins for primary prevention. Cardiovasc Drugs Ther. 2007;21:311-316.

25. Van Geffen EC, Meuwese E, Philbert D, Bouvy ML. Problems with medicine packages: experiences reported to a Dutch medicine reporting system. Ann Pharmacother. 2010;44:104-1109.

26. Atkins L, Fallowfield L. Intentional and non-intentional non-adherence to medication amongst breast cancer patients. Eur J Cancer. 2006;42: 2271-2276.

27. Bates TR, Connaughton VM, Watts GF. Non-adherence to statin therapy: a major challenge for preventive cardiology. Expert Opin Pharmacother. 2009;10:2973-2985.

28. Horne R, Weinman J, Hankins M. The beliefs about medicines questionnaire: the development and evaluation of a new method for assessing the cognitive representation of medication. Psychol Health. 1999;14:1-24.

29. Morisky DE, Ang A, Krousel-Wood M, Ward HJ. Predictive validity of a medication adherence measure in an outpatient setting. $J$ Clin Hypertens (Greenwich). 2008;10:348-354.

30. Gardarsdottir H, Souverein PC, Egberts TC, Heerdink ER. Construction of drug treatment episodes from drug-dispensing histories is influenced by the gap length. J Clin Epidemiol. 2010;63:422-427.

31. Osterberg L, Blaschke T. Adherence to medication. $N$ Engl J Med. 2005;353:487-497. 


\section{Supplementary materials}

Table SI Items to assess experiences and perceptions with regard to the efficacy of antidepressants

\begin{tabular}{|c|c|c|c|c|}
\hline \multirow{2}{*}{$\begin{array}{l}\text { Items, and their factor loadings } \\
\text { All items scored on } 5 \text {-point scales: } 0 \text {, fully disagree; } 4 \text {, fully agree }\end{array}$} & \multicolumn{4}{|c|}{ Factor dimensions } \\
\hline & $\mathbf{J}^{\mathbf{a}}$ & II $^{\mathrm{b}}$ & III $^{c}$ & $\mathbf{I V}^{\mathbf{d}}$ \\
\hline I. The use of antidepressants is necessary for me & 0.66 & 0.38 & 0.21 & 0.12 \\
\hline 2. I am convinced of the efficacy of antidepressants & 0.72 & 0.33 & 0.21 & 0.16 \\
\hline 3. I have doubts about the efficacy of antidepressants ${ }^{\dagger}$ & 0.82 & 0.02 & 0.03 & 0.19 \\
\hline 4. Antidepressants have a limited efficacy ${ }^{\dagger}, * * *$ & 0.45 & -0.35 & 0.15 & 0.15 \\
\hline 5. I expect antidepressants to help & 0.64 & 0.36 & 0.15 & 0.19 \\
\hline 6. I know how antidepressants work & 0.13 & 0.76 & 0.12 & 0.13 \\
\hline 7. I received information about how antidepressants work & 0.18 & 0.67 & 0.06 & 0.12 \\
\hline 8. I know why I have to use antidepressants & 0.42 & 0.64 & 0.14 & -0.03 \\
\hline 9. I am using antidepressants, because I was afraid my complaints would come back & -0.13 & 0.27 & 0.59 & 0.22 \\
\hline 10. Antidepressants prevent my complaints from coming back & 0.47 & 0.35 & 0.50 & 0.09 \\
\hline II. Using antidepressants resolves your problems & 0.28 & -0.03 & 0.70 & 0.09 \\
\hline 12. The longer you use antidepressants, the better they work & 0.18 & 0.04 & 0.67 & 0.05 \\
\hline 13. It took a long time before my antidepressants worked ${ }^{\dagger} * *$ & -0.05 & 0.05 & -0.11 & -0.05 \\
\hline 14. Owing to antidepressants, I have more energy & 0.15 & 0.21 & 0.27 & 0.75 \\
\hline 15. Owing to antidepressants, I sleep better** & 0.14 & -0.04 & -0.06 & 0.78 \\
\hline 16. Because of antidepressants, I feel physically better & 0.33 & 0.18 & 0.35 & 0.57 \\
\hline 17. Because of my antidepressants, I feel mentally better*** & 0.51 & 0.24 & 0.27 & 0.44 \\
\hline$\%$ of variance explained & $34 \%$ & $9 \%$ & $7 \%$ & $6 \%$ \\
\hline Cronbach's alpha & 0.84 & 0.69 & 0.62 & 0.78 \\
\hline
\end{tabular}

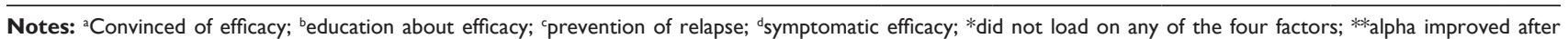
deletion of this item; ***thought to reflect the fourth dimension to a greater extent than the first dimension from a theoretical point of view; ${ }^{\dagger}$ reversed scoring, higher score now indicates more positive perceptions. 
Table S2 Items to assess unintentional and intentional nonadherence

\begin{tabular}{|c|c|c|}
\hline \multirow[t]{2}{*}{ Factor loadings of nonadherence items } & \multicolumn{2}{|c|}{ Nonadherence dimensions } \\
\hline & Unintentional & Intentional \\
\hline \multicolumn{3}{|l|}{ MMAS items } \\
\hline I. Do you sometimes forget to take your antidepressants? (0, no; I, yes) & Excluded $^{\mathrm{a}}$ & \\
\hline 2. Over the past 2 weeks, were there any days when you did not take your antidepressants? ( 0 , no; I, yes) & 0.41 & 0.34 \\
\hline $\begin{array}{l}\text { 3. Have you ever cut back or stopped taking your antidepressants without telling your doctor, } \\
\text { because you felt worse when you took them? }(0, \text { no; I, yes })\end{array}$ & -0.07 & 0.58 \\
\hline 4. When you travel or leave home, do you sometimes forget to bring along your antidepressants? $(0$, no; $I$, yes $)$ & 0.58 & 0.09 \\
\hline 5. Did you take your antidepressants yesterday? ${ }^{\dagger}(0$, yes; 1, no $)$ & 0.16 & 0.26 \\
\hline $\begin{array}{l}\text { 6. When you feel like your symptoms are under control, do you sometimes stop taking your antidepressants? } \\
(0, \text { no; I, yes })\end{array}$ & 0.13 & 0.61 \\
\hline $\begin{array}{l}\text { 7. Taking medication everyday is a real inconvenience for some people. Do you ever feel hassled about } \\
\text { sticking to your antidepressant-treatment plan? }(0, \text { no; I, yes })\end{array}$ & 0.43 & 0.22 \\
\hline $\begin{array}{l}\text { 8. How often do you have difficulty remembering to take all your antidepressants? } \\
\text { ( } 0 \text {, never or seldom; I, once in a while; } 2 \text {, sometimes; } 3 \text { most of the time; } 4 \text {, always) }\end{array}$ & 0.81 & 0.00 \\
\hline \multicolumn{3}{|l|}{ MARS items (all items: 0 , never; I, seldom; 2 , sometimes; 3 , often; 4 , always) } \\
\hline I. I forget to use my antidepressants & 0.70 & 0.18 \\
\hline 2. I adjust the dosage of my antidepressants & 0.04 & 0.67 \\
\hline 3. I stop using antidepressants for a while & 0.08 & 0.69 \\
\hline 4. I decide to skip an antidepressant's dose & 0.35 & 0.43 \\
\hline 5. I take fewer antidepressant tablets than prescribed to me & 0.07 & 0.61 \\
\hline \multicolumn{3}{|l|}{ Additional items } \\
\hline I. I sometimes forgot to take my antidepressants ( 0 , no; I, yes) & 0.87 & -0.09 \\
\hline 2. I forgot whether I had already taken my antidepressants $(0$, no; I, yes $)$ & Excluded ${ }^{b}$ & \\
\hline 3. I intend to use antidepressants in the way prescribed ( 0 , fully agree; 4 , fully disagree) & 0.11 & 0.50 \\
\hline 4. I intend to discontinue using antidepressants prematurely ${ }^{\dagger}(0$, fully disagree; 4 , fully agree $)$ & -0.12 & 0.40 \\
\hline$\%$ of variance explained & $23 \%$ & $16 \%$ \\
\hline Cronbach's alpha & 0.71 & 0.73 \\
\hline
\end{tabular}

Notes: ${ }^{t}$ Reversed scoring, higher score now indicates more nonadherence; aduplicate; bredundant. Items were excluded from the total score if they were duplicate items, had low or ambiguous factor loadings, or improved Cronbach's alpha after deletion. The final calculation of the total scores was as follows: intentional nonadherence = MMAS i3 + MMAS i5 + MMAS i6 + MARS i2 + MARS i3 + MARS i4 + MARS i5 + additional i3 + additional i4; unintentional nonadherence = MMAS i2 + MMAS i4 + MMAS i7 + MMAS i8 + MARS il + additional il.

Abbreviations: MMAS, Morisky Medication Adherence Scale; MARS, Medication Adherence Rating Scale; i, self-evident.

\section{Publish your work in this journal}

Patient Preference and Adherence is an international, peer-reviewed, open access journal focusing on the growing importance of patient preference and adherence throughout the therapeutic continuum. Patient satisfaction, acceptability, quality of life, compliance, persistence and their role in developing new therapeutic modalities and compounds to optimize clinical outcomes for existing disease states are major areas of interest. This journal has been accepted for indexing on PubMed Central. The manuscript management system is completely online and includes a very quick and fair peer-review system. Visit http://www.dovepress.com/ testimonials.php to read real quotes from published authors. 